\begin{tabular}{|c|l|}
\hline Title & Rhodium-Catalyzed A ddition of Arylboronic A cids to N-Sulfonyl A Idimines \\
\hline Author(s) & Ueda, Masato; Saito, A tsushi; Miy aura, Norio \\
\hline Citation & $\begin{array}{l}\text { Synlett, 2000(11), 1637-1639 } \\
\text { https:/doi.org/10.1055/s2000-7949 }\end{array}$ \\
\hline Issue Date & 2000-11 \\
\hline Doc URL & http://hdl.handle.net/2115/14624 \\
\hline Type & article(author version) \\
\hline File Information & synlett_2000_11_1637.pdf \\
\hline
\end{tabular}

Instructions for use 


\section{Rhodium-Catalyzed Addition of Arylboronic Acids to N-Sulfonyl Aldimines}

Masato Ueda, Atsushi Saito, and Norio Miyaura*

Division of Molecular Chemistry, Graduate School of Engineering, Hokkaido University, Sapporo 060-8628, Japan

Fax+81-11-706-6561; E-mail: miyaura@org-mc.eng.hokudai.ac.jp

Received 
Abstract: The addition of arylboronic acids, $\mathrm{ArB}(\mathrm{OH})_{2}$, to N-phenylsulfonyl aldimines, $\quad \mathrm{RCH}=\mathrm{NSO}_{2} \mathrm{Ph} \quad(\mathrm{R}=$ alkyl, aryl, 1-alkenyl), giving $\mathrm{R}(\mathrm{Ar}) \mathrm{CHNHSO}_{2} \mathrm{Ph}$ was carried out at $95{ }^{\circ} \mathrm{C}$ in the presence of a rhodium catalyst. $\left[\mathrm{Rh}(\mathrm{cod})(\mathrm{MeCN})_{2}\right] \mathrm{BF}_{4}$ (3 mol\%) was found to be the best catalyst for aryl aldimines and $\mathrm{Rh}(\mathrm{acac})(\mathrm{coe})_{2} / i-\mathrm{Pr}_{3} \mathrm{P}$ for alkyl and 1-alkenyl aldimines. The analogous reactions of arylboronic esters, such as 1,2-ethanediol and 1,3-propanediol ester, yielded the addition products in the presence of two equivalents of $\mathrm{Et}_{3} \mathrm{~N}$.

Key Words: arylboronic acids, N-sulfonyl aldimines, rhodium-catalyzed addition, diarylmethylamine

The metal-catalyzed reactions, which involve an insertion of the carbon-heteroatom bond to the carbon-transition metal bond, have been studied extensively because the catalyzed reactions are of interest due to their potential application to asymmetric synthesis. The additions of arylstannanes and arylsilanes to aldehydes, imines or enones are catalyzed by rhodium complexes, ${ }^{1} \mathrm{Ni}$ (acac) $)_{2} / \mathrm{PPh}_{3}{ }^{2}$ catalyzes the methylation of aldehydes with trimethylaluminum, and allylstannanes and allylsilanes are added to aldehydes and imines in the presence of $\mathrm{PdCl}_{2}\left(\mathrm{PPh}_{3}\right)_{2}$ or $\mathrm{PtCl}_{2}\left(\mathrm{PPh}_{3}\right)_{2}{ }^{3}$ On the other hand, we recently found that rhodium complexes catalyze various addition reactions of organoboronic acids. The conjugate 1,4-addition of aryland 1-alkenylboronic acids to $\alpha, \beta$-unsaturated ketones, ${ }^{4}$ esters, ${ }^{5}$ and amides, ${ }^{6}$ and 1,2-addition to aldehydes giving secondary alcohols proceed in the presence of a $\mathrm{Rh}$ (acac)/phosphine complex (Eq. 1). ${ }^{7}$ We also reported the addition of $\mathrm{ArSnMe}_{3}$ and $\mathrm{Ar}_{4} \mathrm{BNa}$ to aldimines catalyzed by $\left[\mathrm{Rh}(\mathrm{cod})(\mathrm{MeCN})_{2}\right] \mathrm{BF}_{4} \quad$ (cod=1,5-cyclooctadiene); ${ }^{8}$ however, there were undesirable limitations for organic syntheses, such as the formation of a poisonous residue in stannanes or the availability of functionalized $\mathrm{Ar}_{4} \mathrm{BNa}$ derivatives (Eq. 2).

$<<$ Eqs. 1 and $2>>$

We wish to report here the arylation of N-sulfonyl aldimines with arylboronic acids or their esters catalyzed by $\left[\mathrm{Rh}(\mathrm{cod})(\mathrm{MeCN})_{2}\right] \mathrm{BF}_{4}$. The addition of arylboronic esters proceeded in the presence of $\mathrm{Et}_{3} \mathrm{~N}$, whereas the boronic acids were added smoothly under neutral conditions (Eq. 3).

$$
<<\text { Eq. 2>> }
$$

Table 1 summarizes the additions of $p$-tolylboronic acid and its esters to $4-\mathrm{MeOC}_{6} \mathrm{H}_{4} \mathrm{CH}=\mathrm{NSO}_{2} \mathrm{Ph}$ in the presence of $3 \mathrm{~mol} \%$ of $\left[\mathrm{Rh}(\mathrm{cod})(\mathrm{MeCN})_{2}\right] \mathrm{BF}_{4}$ at $95^{\circ} \mathrm{C}$. The additions of ethanediol ester and the 1,3-propanediol ester resulted in low yields in the absence of $\mathrm{Et}_{3} \mathrm{~N}$, but the presence of $\mathrm{Et}_{3} \mathrm{~N}$ (2 equivs) improved the yields to $87 \%$ and 95\%, respectively (Entries 1 and 2). $\mathrm{K}_{3} \mathrm{PO}_{4}$ (78\%), $\mathrm{KF}(87 \%)$, and $\mathrm{Et}_{3} \mathrm{~N}(95 \%)$ also accelerated the reaction of the 1,3-propanediol ester, 
whereas $\mathrm{PhOK}(5 \%), \mathrm{K}_{2} \mathrm{CO}_{3}(60 \%), \mathrm{LiF}$ (56\%), pyridine (39\%), and $\mathrm{EtN}(i-\mathrm{Pr})_{2}$ (27\%) were not effective. On the other hand, the reaction was significantly slower with the addition of catechol ester or diethanolamine ester (Entries 3-5). Interestingly, boronic acids were found to be the best reagent for the arylation of imines. Although organoboronic acids reversibly generate three moles of water via dehydration to boroxine $(\mathrm{ArBO})_{3}$, the formation of aldehyde via hydrolysis of aldimine ${ }^{8}$ was not observed (Entry 6). Both dry $p$-tolylboronic acid containing more than $80 \%$ of boroxine and that freshly crystallized from water afforded similarly good results in the absence of $\mathrm{Et}_{3} \mathrm{~N}$.

$$
<<\text { Table } 1>>
$$

The effect of rhodium catalysts is summarized in Table 2. Both 1,5-cyclooctadiene (cod) complexes of a cationic rhodium(I) and a neutral rhodium(I) chloride exhibited an excellent catalyst activity, resulting more than 90\% yields (Entries 1 and 2). Rh(acac)(coe) 2 resulted in significantly lower yields (Entry 3), but its combination with a bisphosphine ligand, such as dppm or dppp, catalyzed the reaction efficiently (Entries 4 and 6). A sharp contrast observed in the catalyst efficiencies of the cyclooctadiene complex (Entries 1 and 2) and the cyclooctene complex (Entry 3) indicates that cyclooctadiene sufficiently stabilizes the rhodium(I) species in the absence of a phosphine ligand. The effect of monophosphine ligands is shown in Entries 8-10. The polarization of the C-Rh bond by the donating ligand may enhance the nucleophilicity of the organic group on the rhodium metal. Bulky and donating ligands such as $(i-\mathrm{Pr})_{3} \mathrm{P}$ and $(t-\mathrm{Bu})_{3} \mathrm{P}$ exhibited indeed an exceptionally large accelerating effect for the rhodium-catalyzed addition of arylboronic acids to aldehydes. ${ }^{7 \mathrm{~b}}$ $(t-\mathrm{Bu})_{3} \mathrm{P}$ was not effective for aldimines, presumably due to the instability of $\mathrm{Rh}(\mathrm{I}) / t-\mathrm{Bu}_{3} \mathrm{P}$ complex at the elevated temperature, but the $(i-P r)_{3} \mathrm{P}$ complex catalyzed the reaction efficiently.

$$
<<\text { Table } 2>>
$$

Selected results for the additions of arylboronic acids to arylaldimines in the presence of $3 \mathrm{~mol} \%$ of $\left[\mathrm{Rh}(\mathrm{cod})(\mathrm{MeCN})_{2}\right] \mathrm{BF}_{4}$ are summarized in Table 3. Arylboronic acids were not added to $\mathrm{N}$-alkyl or $\mathrm{N}$-aryl aldimines (Entry 1), but the $\mathrm{N}$-sulfonyl group, and presumably also the $\mathrm{N}$-acyl group, ${ }^{8}$ activates the $\mathrm{C}=\mathrm{N}$ bond for the additions giving the corresponding amines in high yields (Entries 2-10). There was no large difference in yields between electron-rich and -deficient aromatic aldimines (Entries 2-5). The decrease in yields with steric hindrance of $o$-substituents on both aromatic aldimines and arylboronic acids was not significant (Entries 4 and 7).

$$
<<\text { Table } 3>>
$$

The additions to alkyl $\mathbf{3 a}$ and $\alpha, \beta$-unsaturated aldimine $\mathbf{3 b}$ are shown in Eq. 3. The reaction did not proceed for alkyl aldimine or resulted in a complex mixture for $\alpha, \beta$-unsaturated aldimine when a 
cationic rhodium complex or its combination with phosphine ligands was used, but a catalyst in situ generated from Rh(acac)(сое) $)_{2}$ and $i$ - $\mathrm{Pr}_{3} \mathrm{P}$ (Entry 9 in Table 2) cleanly afforded the addition products in high yields. The catalyst achieved a selective 1,2-addition to $\mathrm{C}=\mathrm{N}$ bond, but all attempts at conjugate 1,4-addition to $\mathbf{3 b}$ were unsuccessful.

$$
<<\text { Eq. } 4>>
$$

In addition to our previous reports on 1,4-additions of aryl- and 1-alkenylboronic acids to enones and 1,2-addition to aldehydes, the addition to aldimines was found to be similarly catalyzed by a rhodium complex. Because of the simple experimental procedure using a catalytic amount of a rhodium-binap complex and the tolerance of organoboronic acids to various functional groups, we anticipate the feasibility of catalyzed additions of organoboronic acids to other unsaturated bonds. The asymmetric addition to imines using a chiral phosphine-rhodium complex is currently under investigation.

Representative procedure: A flask charged with $\left[\mathrm{Rh}(\mathrm{cod})(\mathrm{MeCN})_{2}\right] \mathrm{BF}_{4}(0.03 \mathrm{mmol})$ or $\mathrm{Rh}(\mathrm{acac})(\mathrm{coe})_{2}{ }^{7 \mathrm{~b}}(0.03 \mathrm{mmol})$ plus $i-\mathrm{Pr}_{3} \mathrm{P}(0.03 \mathrm{mmol})$, arylboronic acid or ester $(2 \mathrm{mmol})$ and aldimine $^{9}(1.0 \mathrm{mmol})$ was flushed with argon. 1,4-Dioxane $(4 \mathrm{~mL})$ and $\mathrm{Et}_{3} \mathrm{~N}$ (if used, $2 \mathrm{mmol}$ ) were then added. After being stirred for $16 \mathrm{~h}$ at $95^{\circ} \mathrm{C}$, the product was extracted with benzene, washed with brine, and dried over $\mathrm{MgSO}_{4}$. Chromatography over silica gel gave a diarylmethylamine.

\section{References}

(1) a) Oi, S.; Moro, M.; Ono, S.; Inoue, Y. Chem. Lett. 1997, 83. b) Oi, S.; Moro, M.; Inoue, Y. J. Chem. Soc., Chem. Commun. 1997, 1621. c) Moro, M.; Ito, H.; Kawanishi, K.; Oi, T.; Inoue, Y. The abstract of the 76th Annual Meeting of Japan Chemical Society (1999); 2B714. d) Oi, S.; Moro, M.; Fukuhara, M.; Kawanishi, T.; Inoue, Y. Tetrahedron Lett. 1999, 40, 9259. Hayashi, T.; Igarashi, M. J. Am. Chem. Soc. 2000, 122, 976.

(2) Ichiyanagi, T.; Kuniyama, S.; Simizu, M.; Fujisawa, T. Chem. Lett. 1998, 1033.

(3) a) Nakamura, H.; Iwama, H.; Yamamoto, Y. J. Am. Chem. Soc. 1996, 118. 6641. b) Nakamura, H.; Nakamura, K.; Yamamoto, Y. J. Am. Chem. Soc. 1998, 120, 4242. c) Nakamura, K.; Nakamura, H.; Yamamoto, Y. J. Org. Chem. 1999, 64, 2614.

(4) Sakai, M.; Hayashi, H.; Miyaura, N. Organometallics 1997, 16, 4229. b) Y.; Ogasawara, M.; Hayashi, T.; Sakai, M.; Miyaura, N. J. Am. Chem. Soc. 1998, 120, 5579. Batey, R. A.; Thadani, A. N.; Smil, D. V. Org. Lett. 1999, 1, 1683-1686.

(5) Sakuma, S.; Sakai, M.; Miyaura, N. J. Org. Chem. 2000, 65, in 
press.

(6) Sakuma, S.; Takahashi, Y.; Miyaura, N. The abstract of the 77th Annual Meeting of Japan Chemical Society (2000); 2 F507.

(7) a) Sakai, M.; Ueda, M.; Miyaura, N. Angew. Chem. Int. Ed. Engl. 1998, 37, 3297. b) Ueda, M.; Miyaura, N.J. Org. Chem. 2000, 65, 4450.

(8) Ueda, M.; Miyaura, N. J. Organomet. Chem. 2000, 595, 31.

(9) The synthesis of N-sulfonyl aldimines, see: a) Vishwakarama, L. C.; Stringer, O. D.; Davis, F. A. Organic Syntheses 1987, 66, 203. b) Ochiai, M.; Kitagawa, Y. J. Org. Chem. 1999, 64, 3181. Chemla, F.; Hebbe, V.; Normant, J.-F. Synthesis 2000, 75. 
Table 1. Effect of Base ${ }^{a}$

\begin{tabular}{clccc}
\hline \multirow{2}{*}{ entry } & $\begin{array}{l}4-\mathrm{MeC}_{6} \mathrm{H}_{4} \mathrm{~B}(\mathrm{OR})_{2} \\
(\mathrm{OR})_{2}=\end{array}$ & yield $/ \%^{b}$ & & yield $/ \%^{c}$ \\
& & $\mathrm{OCH}_{2} \mathrm{CH}_{2} \mathrm{O}$ & & $\mathrm{Et}_{3} \mathrm{~N}$ \\
2 & $\mathrm{OCH}_{2} \mathrm{CH}_{2} \mathrm{CH}_{2} \mathrm{O}$ & 47 & 87 \\
3 & $\mathrm{OC} \mathrm{Me})_{2} \mathrm{C}(\mathrm{Me})_{2} \mathrm{O}$ & 58 & 95 \\
4 & $\mathrm{OCH}_{2} \mathrm{CH}_{2} \mathrm{NHCH}_{2} \mathrm{CH}_{2} \mathrm{O}$ & 5 & 5 \\
5 & $\mathrm{O}_{2} \mathrm{C}_{6} \mathrm{H}_{4}{ }^{d}$ & 18 & 63 \\
6 & $(\mathrm{OH})_{2}$ & 1 & 20 \\
\hline
\end{tabular}

${ }^{a}$ All reactions were carried out in 1,4-dioxane $(4 \mathrm{ml})$ at $95{ }^{\circ} \mathrm{C}$ for $16 \mathrm{~h}$ in the presence of $4-\mathrm{MeOC}_{6} \mathrm{H}_{4} \mathrm{CH}=\mathrm{NSO}_{2} \mathrm{Ph}(1.0 \mathrm{mmol})$, 4-tolylB(OR $)_{2} \quad(2.0 \mathrm{mmol}), \quad\left[\mathrm{Rh}(\mathrm{cod})(\mathrm{MeCN})_{2}\right] \mathrm{BF}_{4}$ (3 mol\%), and $\mathrm{Et}_{3} \mathrm{~N}$ (if used, $2.0 \mathrm{mmol}$ ). ${ }^{b} \mathrm{GC}$ yields based on the N-sulfonyl imines in the absence of $\mathrm{Et}_{3} \mathrm{~N}$. ${ }^{\mathrm{C}} \mathrm{GC}$ yields in the presence of $\mathrm{E}_{3} \mathrm{~N}$. ${ }^{d}$ A catechol ester. 
Table 2. Effect of Catalysts ${ }^{a}$

\begin{tabular}{|c|c|c|c|}
\hline entry & catalyst & ligand & yield $/ \%^{b}$ \\
\hline 1 & {$\left[\mathrm{Rh}(\mathrm{cod})(\mathrm{MeCN})_{2}\right] \mathrm{BF}_{4}{ }^{c}$} & none & 99 \\
\hline 2 & {$[\mathrm{RhCl}(\mathrm{cod})]_{2}^{c}$} & none & 93 \\
\hline 3 & $\mathrm{Rh}($ acac $)(\text { coe })_{2}{ }^{d}$ & none & 3 \\
\hline 4 & $\operatorname{Rh}($ acac $)(\text { coe })_{2}^{d}$ & $\mathrm{dppm}^{e}$ & 96 \\
\hline 5 & $\mathrm{Rh}($ acac $)(\text { coe })_{2}{ }^{d}$ & $\mathrm{dppe}^{f}$ & 6 \\
\hline 6 & $\operatorname{Rh}($ acac $)(\text { coe })_{2}{ }^{d}$ & $\mathrm{dppp}^{g}$ & 92 \\
\hline 7 & $\operatorname{Rh}($ acac $)(\text { coe })_{2}{ }^{d}$ & $\mathrm{dppf}^{h}$ & 50 \\
\hline 8 & $\operatorname{Rh}($ acac $)(\text { coe })_{2}{ }^{d}$ & $\mathrm{PPh}_{3}$ & 7 \\
\hline 9 & $\operatorname{Rh}($ acac $)(\text { coe })_{2}{ }^{d}$ & $\mathrm{P}(i-\mathrm{Pr})_{3}$ & 88 \\
\hline 10 & $\mathrm{Rh}($ acac $)(\text { coe })_{2}{ }^{d}$ & $\mathrm{P}(t-\mathrm{Bu})_{3}$ & 18 \\
\hline
\end{tabular}

${ }^{a}$ All reactions were carried out in 1,4-dioxane $(4 \mathrm{ml})$ at $95^{\circ} \mathrm{C}$ for $16 \mathrm{~h}$ in the presence of $4-\mathrm{MeOC}_{6} \mathrm{H}_{4} \mathrm{CH}=\mathrm{NSO}_{2} \mathrm{Ph}(1.0 \mathrm{mmol})$, 4-tolyl-B(OH) $)_{2}(2.0 \mathrm{mmol})$, Rh complex (3 mol\%), and ligand (3 mol\%).

${ }^{b} \mathrm{GC}$ yields based on the imine.

${ }^{c}$ cod $=1,5$-cyclooctadiene.

${ }^{d}$ coe $=$ cyclooctene.

${ }^{e}$ Bis(diphenylphosphino)methane.

${ }_{1} 1,2$-Bis(diphenylphosphino)-ethane.

${ }^{g}$ 1,3-Bis(diphenylphosphino)propane.

${ }^{h} 1,1$ '-Bis(diphenylphosphino)ferrocene. 
Table 3. Addition of Arylboronic Acids to Arylaldimines ${ }^{a}$

\begin{tabular}{|c|c|c|c|}
\hline entry & $\operatorname{ArB}(\mathrm{OH})_{2}$ & Imine & yield $/ \%^{b}$ \\
\hline 1 & $4-\mathrm{MeC}_{6} \mathrm{H}_{4} \mathrm{~B}(\mathrm{OH})_{2}$ & $\mathrm{PhCH}=\mathrm{NPh}$ & 0 \\
\hline 2 & & $4-\mathrm{MeOC}_{6} \mathrm{H}_{4} \mathrm{CH}=\mathrm{NSO}_{2} \mathrm{Me}$ & 79 \\
\hline 3 & & $4-\mathrm{MeOC}_{6} \mathrm{H}_{4} \mathrm{CH}=\mathrm{NSO}_{2} \mathrm{Ph}$ & 95 \\
\hline 4 & & $2-\mathrm{MeC}_{6} \mathrm{H}_{4} \mathrm{CH}=\mathrm{NSO}_{2} \mathrm{Ph}$ & 90 \\
\hline 5 & & $4-\mathrm{F}_{3} \mathrm{CC}_{6} \mathrm{H}_{4} \mathrm{CH}=\mathrm{NSO}_{2} \mathrm{Ph}$ & 99 \\
\hline 6 & & 1-naphthylCH= $\mathrm{NSO}_{2} \mathrm{Ph}$ & 68 \\
\hline 7 & $2-\mathrm{MeC}_{6} \mathrm{H}_{4} \mathrm{~B}(\mathrm{OH})_{2}$ & $4-\mathrm{MeOC}_{6} \mathrm{H}_{4} \mathrm{CH}=\mathrm{NSO}_{2} \mathrm{Ph}$ & 75 \\
\hline 8 & $4-\mathrm{FC}_{6} \mathrm{H}_{4} \mathrm{~B}(\mathrm{OH})_{2}$ & $4-\mathrm{MeOC}_{6} \mathrm{H}_{4} \mathrm{CH}=\mathrm{NSO}_{2} \mathrm{Ph}$ & 87 \\
\hline 9 & $3-\mathrm{ClC}_{6} \mathrm{H}_{4} \mathrm{~B}(\mathrm{OH})_{2}{ }^{c}$ & $4-\mathrm{MeOC}_{6} \mathrm{H}_{4} \mathrm{CH}=\mathrm{NSO}_{2} \mathrm{Ph}$ & 96 \\
\hline 10 & $4-\mathrm{CF}_{3} \mathrm{C}_{6} \mathrm{H}_{4} \mathrm{~B}(\mathrm{OH})_{2}$ & $4-\mathrm{MeOC}_{6} \mathrm{H}_{4} \mathrm{CH}=\mathrm{NSO}_{2} \mathrm{Ph}$ & 87 \\
\hline
\end{tabular}

${ }^{a}$ All reactions were carried out at $95^{\circ} \mathrm{C}$ for $16 \mathrm{~h}$ in the presence of an imine $(1.0 \mathrm{mmol})$, arylboronic acid $(2.0 \mathrm{mmol})$, and [Rh(cod)-(MeCN) $)_{2} \mathrm{BF}_{4}$ (3 mol\%) in 1,4-dioxane (4 ml). ${ }^{b}$ Isolated yields based on the imines. ${ }^{c} 3-\mathrm{ClC}_{6} \mathrm{H}_{4} \mathrm{~B}(\mathrm{OH})_{2} \quad(3.0 \mathrm{mmol})$ was used. The reaction resulted in $47 \%$ with 2 equivalents of the boronic acid. 
$\stackrel{\substack{\mathrm{Rh}(\mathrm{acac}) / \mathrm{dppf} \text { at } 80^{\circ} \mathrm{C} \\ \text { or } \mathrm{Rh}(\mathrm{acac}) / t-\mathrm{Bu}_{3} \mathrm{P} \text { at r.t. }}}{\mathrm{ArB}(\mathrm{OH})_{2}}$

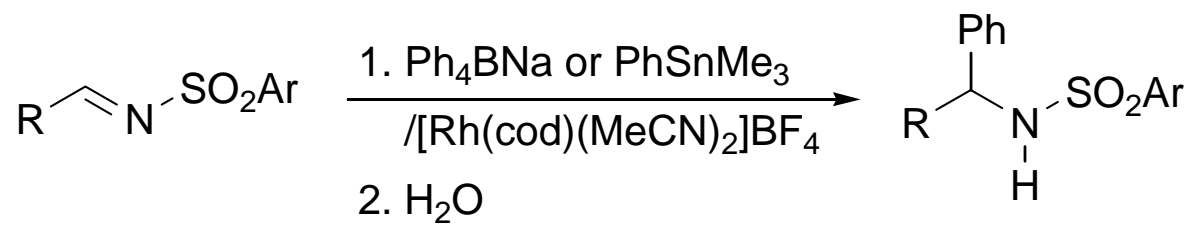

1. $\operatorname{Ar} B(O R)_{2}$

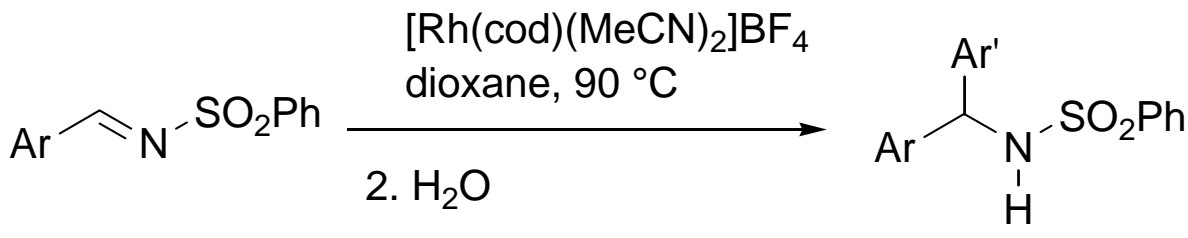

1

2
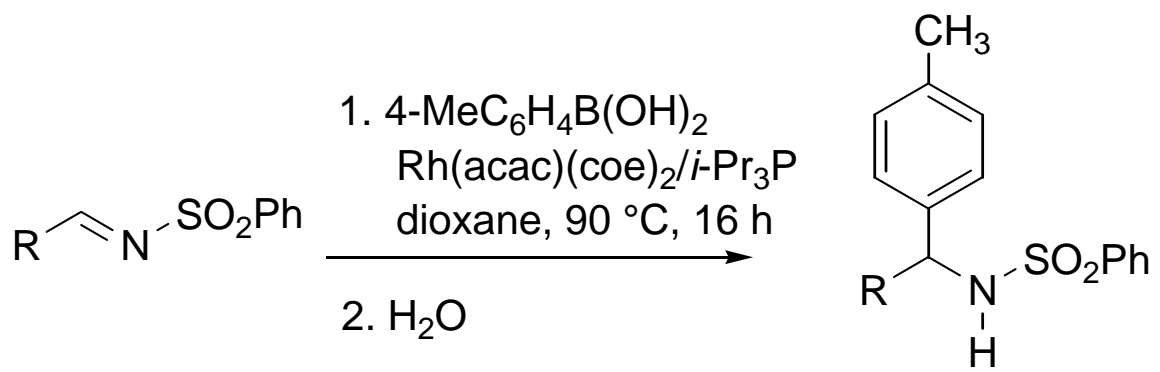

3a: R=cyclohexyl

4a $72 \%$

3b: $\mathrm{R}=(E)-\mathrm{CH}=\mathrm{CHPh}$

4b $90 \%$ 